\title{
Resilience to childhood adversity
}

\section{Insight from gene-environmental interactions in depression and post-traumatic stress disor- der}

Catherine Anne Wassenaar

Faculty Reviewer: Javeed Sukhera, MD, FRCPC (Department of Psychiatry)

\section{ABSTRACT}

Despite being linked to several negative long-term physical and psychological pathologies in adulthood, childhood adversity elicits variable responses in the sufferer. When searching for explanations for this heterogeneity, the concept of resilience has been postulated as a potential mitigating factor. Gene-environmental interactions are a promising avenue in the study of resilience. The premise of gene-environmental research is that interindividual variability in the response to an environmental stressor is due to an individual's genetic make-up exacerbating or buffering the impact of that stressor. Herein, gene-environmental findings are illustrated in the context of depression and post-traumatic stress disorder (PTSD). Many of the gene loci found to interact with childhood adversity influence both depression and PTSD possibly due to the high degree of shared heritability between these psychopathologies. Variation in the serotonin transporter gene, $S L C 6 A 4$, and in $F K B P 5$, a gene coding for a glucocorticoid receptor binding protein, interacts with childhood adversity to influence the development and symptomology of depression and of PTSD. Findings in the field of gene-environmental interactions has led to a proposed 3-hit model whereby 3 hits, genetics, early life experiences and later life stressors, interact to determine whether an individual is vulnerable or resilient to the development of psychopathology. As limitations with the current research are addressed and complementary lines of research are integrated, the insight gained on childhood adversity has the potential to better predict children at risk of the long-term sequelae of adversity and to inform potential intervention and prevention strategies.

\section{INTRODUCTION}

Seminal work from the Adverse Childhood Experiences study demonstrated that exposure to categories of childhood adversity-specifically, psychological, physical or sexual abuse, household violence, substance abuse, mental illness or criminal activity, and parental separation and divorce-is associated with an increased risk of physical and psychological pathologies and unhealthy behaviours in adulthood ${ }^{1,2}$ and with premature mortality. ${ }^{3}$ Interestingly, studies on childhood adversity demonstrate broad heterogeneity in the responses to and long-term consequences of adversity-this heterogeneity has generated research into factors underlying interindividual differences in the vulnerability to adversity and into the concept of resilience. ${ }^{4,5}$ While there is currently a lack of consensus on how best to define and measure resilience, ${ }^{6,7}$ resilience is generally inferred when an individual has a relatively good outcome or good functioning after serious adversity, and resilience research aims to explain interindividual differences in the impact of established risk factors on health outcomes. ${ }^{89}$ As such, quantification of risk factors is critical to accurately infer resilience, or else what is inferred as resilience may represent variation in risk exposure. ${ }^{8,10}$

Over the years resilience research has shifted from psychosocial factors (eg relationships, self-regulation and self-efficacy $)^{11}$ to genetic and epigenetic influences within neurotransmitter systems and the hypothalamic-pituitary-adrenal (HPA) axis to gene-environmental interactions, which posit that interindividual variability in the response to an environmental stressor is due to an individual's genetic make-up exacerbating or buffering the impact of that stressor. ${ }^{6,12-14}$ These latter avenues of research may provide insight into the molecular underpinnings of resilience. Given the diversity in potential stressors, outcomes and demographic groups to study, the field of resilience research is justifiably broad. This paper focuses on gene-environmental interactions in the area of mental health, specifically depression and post-traumatic stress disorder (PTSD), and how research findings are informing a working model of resilience.

\section{GENE-ENVIRONMENTAL INTERACTIONS IN DEPRESSION}

Childhood adversity is associated with symptoms of depression and with the risk of depressive disorders. ${ }^{1,15}$ In 2003, Caspi et al published a landmark paper that fostered an explosion related to gene-environmental interactions in depression research. Emerging research has since identified genetic variants within neurotransmitter systems, neural plasticity and stress response pathways that influence the environmental risk of depression. ${ }^{16}$ This paper focuses on key findings in the serotonergic system and in the HPA axis. Caspi et al investigated the 5-HTTLPR polymorphism, a repeat polymorphism in the promoter region of the serotonin transporter gene, SLC6A4, which is coded as short (S) or long (L) and is associated with transcriptional efficiency. ${ }^{17}$ Caspi et al found a significant interaction between $5-H T T L P R$ and maltreatment experiences in childhood on the occurrence of past-year depressive episodes in adulthood whereby individuals with the 5-HTTLPR LL genotype appeared to be unaffected by childhood adversity compared to individuals with the SS and SL genotypes. ${ }^{18}$ Subsequent investigations and meta-analyses have offered additional support for the moderating role of the $5-H T T L P R$ polymorphism on the relationship between stress and depression. ${ }^{19}$ 
Within the HPA axis, genetic variation in glucocorticoid receptor regulation interacts with childhood adversity to influence depression. The glucocorticoid receptor is an important receptor within the HPA axis in times of stress. ${ }^{20}$ The receptor is kept inactive within the cytosol when bound by FK506-binding protein 5 (FKBP5), and glucocorticoid sensitivity is affected by polymorphisms within this binding protein, such as the FKBP5 rs1360780 polymorphism. ${ }^{21,22}$ The FKBP5 rs1360780 genotype modifies the association between childhood physical abuse and depressive symptoms and the risk for major depressive disorder-individuals with the rs1360780 CC and CT genotypes appear less vulnerable to developing depressive symptoms and more resilient to major depression following childhood physical abuse. ${ }^{23}$ Variation in FKBP5 also interacts with traumatic life events that predominantly occurred in childhood to influence the onset of depression. ${ }^{24}$

\section{GENE-ENVIRONMENTAL INTERACTIONS IN PTSD}

A history of childhood adversity is also among the risk factors for developing PTSD following trauma, ${ }^{25,26}$ leading to the theory that elevated stress in childhood may interact with genetic factors to create an emotional circuit that is highly responsive to stress and increases the risk of trauma-related psychopathology in adulthood. ${ }^{27}$ The demonstration by Caspi et al that the 5-HTTLPR serotonin transporter polymorphism interacts with childhood adversity to influence depression generated interest in pursuing such interaction studies in PTSD. ${ }^{18,28}$ Many of the gene loci found to interact with childhood adversity to influence PTSD are the same as those discovered to influence depression, possibly due to the high degree of shared heritability in PTSD and major depression. ${ }^{29}$

As it does with depression, the 5-HTTLPR polymorphism interacts with childhood adversity to influence the risk for PTSD. ${ }^{28,30}$ Similarly, genetic variation in the glucocorticoid receptor co-chaperone FKBP5 also interacts with childhood adversity to influence PTSD in adulthood. ${ }^{31-33}$ In particular, the rs9470080 polymorphism in FKBP5 interacts with childhood adversity to influence lifetime diagnosis of PTSD and PTSD symptomology. ${ }^{31,33}$ To illustrate, Boscarino et al report a complex interaction between FKBP5 rs9470080, trauma experience, childhood adversity and neuroticism on PTSD32 whereby the FKBP5 rs9470080 CC genotype appears to be resilient to childhood adversity with similar PTSD outcomes regardless of the severity of childhood adversity, ${ }^{32}$ and the TT genotype appears susceptible to both positive and negative environments as this genotype has a comparatively lower risk of PTSD in the absence of childhood adversity and a comparatively higher risk in the presence of childhood adversity. ${ }^{33}$

\section{DISCUSSION OF GENE-ENVIRONMENTAL FINDINGS}

Research into gene-environmental interactions on psychopathology has led to the development of a 3-hit model whereby an individual's genetics interact with early life experiences to influence susceptibility to later life stressors. The combined effects of all 3 hits influence whether an individual is vulnerable or resilient to the development of psychopathology. ${ }^{34}$ Early support for this theory of
3 interacting hits is provided by interaction studies demonstrating that genetic variation in the serotonin transporter interacts with childhood adversity and with adversity in adulthood to influence depressive symptoms. ${ }^{35,36}$

While this article focused on depression and PTSD, it remains to be determined whether the gene variants presented herein act more broadly as a "genetic hit" to influence additional psychological and possibly even physical pathologies. Early evidence suggests that variation in the serotonin transporter may have a global impact on the risk for psychopathology as the 5-HTTLPR variant also interacts with childhood adversity to influence other psychopathologies, such as suicide, anxiety sensitivity and dissociative experiences. ${ }^{18,30,37-39}$ Furthermore, due to limitations in the statistical design of many resilience studies, it is often not possible to differentiate whether a genetic factor influences vulnerability to adversity specifically or susceptibility to both positive and negative experiences, ${ }^{4}$ which has practical implications for the utility of any potential interventions.

Key aspects of the environmental portion of gene-environmental interactions must also be addressed to further improve the 3-hit model and ultimately to inform intervention strategies. To date most studies on childhood adversity have utilized composite measures of adversity, such as the Childhood Trauma Questionnaire. This research has not been sufficiently powered to test interactions with the five separate components of abuse and neglect. In future, meta-analyses may reveal whether specific types of childhood adversity may be of greater benefit to screen for and target for interventions. Child abuse and neglect are higher among low-income environments, ${ }^{40}$ and the role of socioeconomic status, specifically whether socioeconomic status may be confounding gene-environmental interactions, remains to be determined. ${ }^{27,41}$ Finally, greater experimental use of resilience scales, such as the Connor-Davidson Resilience Scale, ${ }^{42,43}$ is necessary to determine the utility of these scales to predict the risk of psychopathology and to monitor the efficacy of potential interventions.

\section{CONCLUSIONS}

Complementary lines of research have the potential to provide insight into the physiological and molecular underpinnings of resilience and the gene-environmental interactions presented in this article. Research into the impact of childhood adversity on stress reactivity in adulthood may provide biological insight into changes in the stress response pathway. ${ }^{44-46}$ Epigenetics research has the potential to elucidate how childhood adversity as an environmental stressor may be shaping gene expression within stress-response pathways to influence psychopathology in adulthood. ${ }^{47-51}$ Longitudinal cohort studies, such as the Nurses Health Study II, ${ }^{52}$ with genotype data and repeated measurements of epigenetic markers, stress reactivity, adversity and outcomes, should help to bring together these complementary lines of research to develop a dynamic understanding of the relationship between genetics, epigenetics and environmental exposures on resilience. Together these avenues of research offer the potential to better predict children at risk of 


\section{developing the long-term sequelae of adversity and to inform inter- vention strategies.}

\section{REFERENCES}

1. Felitti VJ, Anda RF, Nordenberg D, et al. Relationship of childhood abuse and household dysfunction to many of the leading causes of death in adults. The adverse childhood experiences (ACE) study. Am J Prev Med. 1998;14(4):245-58.

2. Anda RF, Croft JB, Felitti VJ, et al. Adverse childhood experiences and smoking during adolescence and adulthood. JAMA. 1999;282(17):16528

3. Brown DW, Anda RF, Tiemeier H, et al. Adverse childhood experiences and the risk of premature mortality. Am J Prev Med. 2009;37(5):389-96.

4. Rutter M. Resilience as a dynamic concept. Dev Psychopathol. 2012;24(2):335-44

5. Shonkoff JP, Boyce WT, McEwen BS. Neuroscience, molecular biology, and the childhood roots of health disparities: building a new framework for health promotion and disease prevention. JAMA. 2009;301(21):2252-9.

6. Kim-Cohen J, Turkewitz R. Resilience and measured gene-environment interactions. Dev Psychopathol. 2012;24(4):1297-306.

7. Walsh WA, Dawson J, Mattingly MJ. How are we measuring resilience following childhood maltreatment? Is the research adequate and consistent? What is the impact on research, practice, and policy? Trauma Violence Abuse. 2010;11(1):27-41.

8. Rutter M. Implications of resilience concepts for scientific understanding. Ann N Y Acad Sci. 2006;1094:1-12.

9. Luthar SS, Sawyer JA, Brown PJ. Conceptual issues in studies of resilience: past, present, and future research. Ann N Y Acad Sci. 2006;1094:105-15.

10. Rutter M. Resilience, competence, and coping. Child Abuse Negl. 2007;31(3):205-9.

11. National Scientific Council on the Developing Child. Supportive relationships and active skill-building strengthen the foundations of resilience: Working paper 13. 2015

12. Feder A, Nestler EJ, Charney DS. Psychobiology and molecular genetics of resilience. Nat Rev Neurosci. 2009;10(6):446-57.

13. Masten AS. Resilience in developing systems: Progress and promise as the fourth wave rises. Dev Psychopathol. 2007;19(3):921-30.

14. Rutter M, Moffitt TE, Caspi A. Gene-environment interplay and psychopathology: multiple varieties but real effects. J Child Psychol Psychiatry. 2006;47(3-4):226-61.

15. Chapman DP, Whitfield CL, Felitti VJ, et al. Adverse childhood experiences and the risk of depressive disorders in adulthood. J Affect Disord. 2004;82(2):217-25.

16. Lopizzo N, Bocchio Chiavetto L, Cattane N, et al. Gene-environment interaction in major depression: focus on experience-dependent biological systems. Front Psychiatry. 2015;6:68.

17. Lesch KP, Bengel D, Heils A, et al. Association of anxiety-related traits with a polymorphism in the serotonin transporter gene regulatory region. Science. 1996;274(5292):1527-31

18. Caspi A, Sugden K, Moffitt TE, et al. Influence of life stress on depression: moderation by a polymorphism in the 5 -htt gene. Science. 2003;301(5631):386-9.

19. Karg K, Burmeister M, Shedden K, et al. The serotonin transporter promoter variant (5-HTTLPR), stress, and depression meta-analysis revisited: evidence of genetic moderation. Arch Gen Psychiatry.
2011;68(5):444-54.

20. Myers B, McKlveen JM, Herman JP. Glucocorticoid actions on synapses, circuits, and behavior: implications for the energetics of stress. Front Neuroendocrinol. 2014;35(2):180-96.

21. Binder EB, Salyakina D, Lichtner P, et al. Polymorphisms in FKBP5 are associated with increased recurrence of depressive episodes and rapid response to antidepressant treatment. Nat Genet. 2004;36(12):1319-25.

22. Denny WB, Valentine DL, Reynolds PD, et al. Squirrel monkey immunophilin FKBP51 is a potent inhibitor of glucocorticoid receptor binding. Endocrinology. 2000;141(11):4107-13.

23. Appel K, Schwahn C, Mahler J, et al. Moderation of adult depression by a polymorphism in the FKBP5 gene and childhood physical abuse in the general population. Neuropsychopharmacology. 2011;36(10):198291.

24. Zimmermann P, Bruckl T, Nocon A, et al. Interaction of FKBP5 gene variants and adverse life events in predicting depression onset: results from a 10-year prospective community study. Am J Psychiatry. 2011;168(10):1107-16.

25. Breslau N, Chilcoat HD, Kessler RC, et al. Previous exposure to trauma and PTSD effects of subsequent trauma: results from the detroit area survey of trauma. Am J Psychiatry. 1999;156(6):902-7.

26. Cougle JR, Timpano KR, Sachs-Ericsson N, et al. Examining the unique relationships between anxiety disorders and childhood physical and sexual abuse in the national comorbidity survey-replication. Psychiatry Res. 2010;177(1-2):150-5.

27. Gillespie CF, Phifer J, Bradley B, et al. Risk and resilience: genetic and environmental influences on development of the stress response. Depress Anxiety. 2009;26(11):984-92.

28. Xie P, Kranzler HR, Poling J, et al. Interactive effect of stressful life events and the serotonin transporter 5-HTTLPR genotype on posttraumatic stress disorder diagnosis in 2 independent populations. Arch Gen Psychiatry. 2009;66(11):1201-9.

29. Koenen KC, Fu QJ, Ertel K, Lyons MJ, et al. Common genetic liability to major depression and posttraumatic stress disorder in men. J Affect Disord. 2008;105(1-3):109-15.

30. Xie P, Kranzler HR, Farrer L, et al. Serotonin transporter 5-HTTLPR genotype moderates the effects of childhood adversity on posttraumatic stress disorder risk: a replication study. Am J Med Genet B Neuropsychiatr Genet. 2012;159B(6):644-52.

31. Binder EB, Bradley RG, Liu W, et al. Association of FKBP5 polymorphisms and childhood abuse with risk of posttraumatic stress disorder symptoms in adults. JAMA. 2008;299(11):1291-305.

32. Boscarino JA, Erlich PM, Hoffman SN, et al. Association of FKBP5, COMT and CHRNA5 polymorphisms with PTSD among outpatients at risk for PTSD. Psychiatry Res. 2011;188(1):173-4.

33. Xie P, Kranzler HR, Poling J, et al. Interaction of FKBP5 with childhood adversity on risk for post-traumatic stress disorder. Neuropsychopharmacology. 2010;35(8):1684-92.

34. Daskalakis NP, Bagot RC, Parker KJ, et al. The three-hit concept of vulnerability and resilience: toward understanding adaptation to early-life adversity outcome. Psychoneuroendocrinology. 2013;38(9):1858-73.

35. Starr LR, Hammen C, Conway CC, et al. Sensitizing effect of early adversity on depressive reactions to later proximal stress: moderation by polymorphisms in serotonin transporter and corticotropin releasing hormone receptor genes in a 20-year longitudinal study. Dev Psychopathol. 2014 Nov;26(4 Pt 2):1241-54.

36. Grabe HJ, Schwahn C, Mahler J, et al. Moderation of adult depression by the serotonin transporter promoter variant (5-HTTLPR), childhood abuse and adult traumatic events in a general population sample. Am J 
Med Genet B Neuropsychiatr Genet. 2012;159B(3):298-309.

37. Lochner C, Seedat S, Hemmings SM, et al. Investigating the possible effects of trauma experiences and 5-HTT on the dissociative experiences of patients with OCD using path analysis and multiple regression. Neuropsychobiology. 2007;56(1):6-13.

38. Roy A, Hu XZ, Janal MN, et al. Interaction between childhood trauma and serotonin transporter gene variation in suicide. Neuropsychopharmacology. 2007;32(9):2046-52.

39. Stein MB, Schork NJ, Gelernter J. Gene-by-environment (serotonin transporter and childhood maltreatment) interaction for anxiety sensitivity, an intermediate phenotype for anxiety disorders. Neuropsychopharmacology. 2008;33(2):312-9.

40. Sedlak AJ, Mettenburg J, Basena M, et al. Fourth national incidence study of child abuse and neglect (NIS-4): report to congress. Washington, DC: U.S. Department of Health and Human Services, Administration for Children and Families, 2010.

41. Cicchetti D. Annual research review: Resilient functioning in maltreated children--past, present, and future perspectives. J Child Psychol Psychiatry. 2013;54(4):402-22.

42. Connor KM, Davidson JR. Development of a new resilience scale: The Connor-Davidson resilience scale (CD-RISC). Depress Anxiety. 2003;18(2):76-82.

43. Campbell-Sills L, Stein MB. Psychometric analysis and refinement of the Connor-Davidson resilience scale (CD-RISC): validation of a 10item measure of resilience. J Trauma Stress. 2007;20(6):1019-28.

44. Klaassens ER. Bouncing back - trauma and the HPA-axis in healthy adults. Eur J Psychotraumatol. 2010;1:10.3402/ejpt.vli0.5844.

45. Voellmin A, Winzeler K, Hug E, et al. Blunted endocrine and cardiovascular reactivity in young healthy women reporting a history of childhood adversity. Psychoneuroendocrinology. 2015;51:58-67.

46. Suzuki A, Poon L, Papadopoulos AS, et al. Long term effects of childhood trauma on cortisol stress reactivity in adulthood and relationship to the occurrence of depression. Psychoneuroendocrinology. 2014;50:289-99.

47. Perroud N, Paoloni-Giacobino A, Prada P, et al. Increased methylation of glucocorticoid receptor gene (NR3Cl) in adults with a history of childhood maltreatment: a link with the severity and type of trauma. Transl Psychiatry. 2011;1:e59.

48. Vukojevic V, Kolassa IT, Fastenrath M, et al. Epigenetic modification of the glucocorticoid receptor gene is linked to traumatic memory and post-traumatic stress disorder risk in genocide survivors. J Neurosci. 2014;34(31):10274-84.

49. Radtke KM, Schauer M, Gunter HM, et al. Epigenetic modifications of the glucocorticoid receptor gene are associated with the vulnerability to psychopathology in childhood maltreatment. Transl Psychiatry. 2015;5:e571.

50. Palma-Gudiel H, Cordova-Palomera A, Leza JC, et al. Glucocorticoid receptor gene ( $\mathrm{NR} 3 \mathrm{Cl}$ ) methylation processes as mediators of early adversity in stress-related disorders causality: A critical review. Neurosci Biobehav Rev. 2015;55:520-35.

51. Mehta D, Klengel T, Conneely KN, et al. Childhood maltreatment is associated with distinct genomic and epigenetic profiles in posttraumatic stress disorder. Proc Natl Acad Sci U S A. 2013;110(20):8302-7.

52. Koenen KC, De Vivo I, Rich-Edwards J, et al. Protocol for investigating genetic determinants of posttraumatic stress disorder in women from the Nurses' Health Study II. BMC Psychiatry. 2009;9:29.

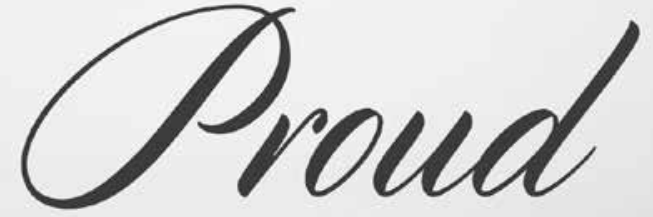

to be a part of your medical journey

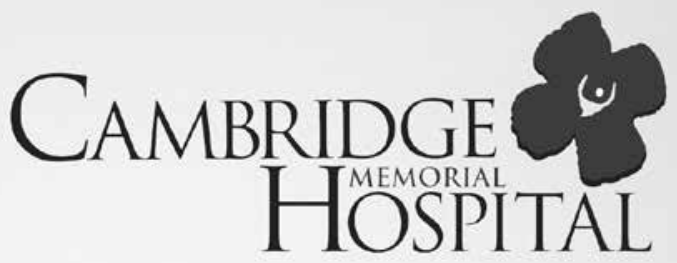

